\title{
Population structure of rumen Escherichia coli associated with subacute ruminal acidosis (SARA) in dairy cattle
}

\author{
E. Khafipour, ${ }^{\star}$ J. C. Plaizier, ${ }^{*}$ P. C. Aikman, $\dagger$ and D. O. Krause ${ }^{*} \ddagger^{1}$ \\ *Department of Animal Science, University of Manitoba, Winnipeg, MB, R3T 2N2 Canada \\ †School of Agriculture, Policy and Development, University of Reading, Earley Gate, Reading, RG6 6AR United Kingdom \\ ‡Department of Medical Microbiology, University of Manitoba, Winnipeg, MB, R3T 2N2 Canada
}

\section{ABSTRACT}

Previous studies indicated that only subacute ruminal acidosis (SARA), induced by feeding a high-grain diet, is associated with an inflammatory response and increased abundance of Escherichia coli in the rumen. We hypothesized that ruminal E. coli in grain pellet-induced SARA carried virulence factors that potentially contribute to the immune activation during SARA. One hundred twenty-nine E. coli isolates were cultured from the rumens of 8 cows (4 animals per treatment) in which SARA had been nutritionally induced by feeding a high-grain diet (GPI-SARA) or a diet containing alfalfa pellets (API-SARA). The population structure of the $E$. coli was evaluated with the $\mathrm{ABD}$ genotyping system and repetitive sequence-based (rep)-PCR fingerprinting. Twenty-five virulence factors were evaluated with PCR. Escherichia coli numbers were higher in the GPI-SARA treatment than in the API-SARA treatment. The genetic structure of the $E$. coli was significantly different between SARA challenge models. Isolates from GPI-control (46\%), API-control $(70 \%)$, and API-SARA (53\%) were closely related and fell into one cluster, whereas isolates from GPI-SARA (54\%) grouped separately. The ABD typing indicated a shift from an A-type E. coli population to a B1-type population only due to GPI-SARA. Of the 25 virulence factors tested, curli fiber genes were highly associated with GPI. Curli fibers were first identified in E. coli mastitis isolates and are potent virulence factors that induce a range of immune responses. Results suggest that under low rumen $\mathrm{pH}$ conditions induced by a grain diet, there is a burst in the number of $E$. coli with virulence genes that can take advantage of these rumen conditions to trigger an inflammatory response.

Key words: cattle, subacute ruminal acidosis, Escherichia coli, virulence genes

Received May 13, 2010.

Accepted October 4, 2010.

${ }^{1}$ Corresponding author: denis_krause@umanitoba.ca

\section{INTRODUCTION}

Subacute ruminal acidosis is a metabolic disease in high-producing dairy cattle that results in reductions in feed intake and milk production, and has been defined as a disorder associated with low rumen $\mathrm{pH}$ (Plaizier et al., 2008). During low rumen $\mathrm{pH}$, gram-negative bacteria lyse more rapidly, increasing the concentration of LPS in the rumen (Nagaraja and Titgemeyer, 2007). Low pH, high osmotic pressure, and the presence of LPS in the rumen fluid are associated with the development of microlesions and parakeratosis in the rumen epithelium (Kleen et al., 2003). A reduction in barrier function of the rumen epithelium potentially allows LPS to translocate into blood and stimulate an inflammatory response (Plaizier et al., 2008; Khafipour et al., 2009a,b). When SARA was induced by feeding grain pellets (GPI-SARA) or by feeding alfalfa pellets (API-SARA), both diets resulted in low rumen $\mathrm{pH}$ and increased rumen osmolarity and LPS but only the GPI-SARA resulted in an inflammatory response (Khafipour et al., 2009a,b). Thus, low rumen $\mathrm{pH}$ and high osmolarity by themselves are not enough to explain an inflammatory response.

Molecular microbial analysis of the rumen microbiome demonstrated significant differences in the microbial composition of the rumen with these 2 diets, particularly in the Firmicutes and Bacteroidetes phyla (Khafipour et al., 2009c). Of particular note was the increased abundance of Escherichia coli in the GPISARA group. In this manuscript we evaluated the genetic composition of these $E$. coli and the virulence factors they carry during GPI- vs. API-SARA.

\section{MATERIALS AND METHODS}

Animal experiments were conducted at the University of Manitoba Glenlea Dairy Research Unit in accordance with the guidelines of the Canadian Council on Animal Care (1993). The nutritional models, diet composition, and animal management have been described previously (Khafipour et al., 2009a,b). In brief, 
SARA was nutritionally induced in 4 rumen-canulated dairy cows by feeding a high-grain diet (grain-pellet challenge: GPI) or a diet containing alfalfa pellets (alfalfa-pellet challenge: API) in 2 separate experiments (total of 8 animals). In both experiments, animals were fed once daily at $0900 \mathrm{~h}$. In the GPI experiment, cows received a basal diet with a forage-to-concentrate ratio of 50:50. The ration consisted of $25 \%$ as alfalfa silage, $25 \%$ as barley silage, $40 \%$ as an energy supplement, and $10 \%$ as a protein supplement. Subacute ruminal acidosis was induced by replacing $21 \%$ of the dietary DM with wheat-barley pellets. In the API experiment, cows received a basal diet that consisted of $50 \%$ of the $\mathrm{DM}$ as concentrate and $50 \%$ as chopped alfalfa hay. The concentrate fraction consisted of $39 \%$ as an energy supplement, $4.5 \%$ as a protein supplement, and $6.5 \%$ as roasted soybeans. Subacute ruminal acidosis was induced by replacing $42 \%$ of the alfalfa hay DM with alfalfa pellets without changing the forage-to-concentrate ratio or the dietary content of starch.

Thirty-two rumen fluid samples were collected immediately before and at $6 \mathrm{~h}$ after feeding during the control (GPI-control and API-control) and SARA periods. Rumen $\mathrm{pH}$ was monitored continuously using indwelling pH probes (Khafipour et al., 2009a). Average rumen $\mathrm{pH}$ and time spent below $\mathrm{pH} 5.6$ were 6.17 and $118 \mathrm{~min} / \mathrm{d}$, respectively, in GPI-control; 6.35 and $112 \mathrm{~min} / \mathrm{d}$, respectively, in API-control; 5.97 and 279 $\mathrm{min} / \mathrm{d}$, respectively, in GPI-SARA; and 5.85 and 510 $\mathrm{min} / \mathrm{d}$, respectively, in API-SARA (Khafipour et al., 2009a, b). For the analysis of E. coli, rumen samples were strained through 4 layers of sterile cheesecloth, mixed with an equal volume of $50 \%$ sterile glycerol in a 15-mL screw-cap polypropylene tube and stored at $-80^{\circ} \mathrm{C}$ until used for enumeration and isolation of $E$. coli.

\section{Isolation and Enumeration of E. coli}

Glycerol stocks were thawed on the bench top and E. coli/coliform chromogenic medium (CM0956, Oxide Inc., Nepean, ON, Canada) was used for enumeration. Buffered peptone water ( $\mathrm{pH}$ 7.2, Difco Laboratories, Detroit, MI) was used to make decimal dilutions in 2-mL deep-well plates. Plates were covered with aluminum foil and sterilized at $121^{\circ} \mathrm{C}$ and $103.4 \mathrm{kPa}$ for 15 min before use. A $100-\mu \mathrm{L}$ sub-sample of the thawed glycerol stocks was inoculated into $900 \mu \mathrm{L}$ of $2 \%$ buffered peptone water and serially diluted to $10^{-7}$. Dilutions from $10^{-1}$ to $10^{-7}$ were plated onto medium by dispensing 10 droplets of $10 \mu \mathrm{L}$ each (Herigstad et al., 2001). Following adsorption of the droplets onto the medium, plates were inverted and incubated at $39^{\circ} \mathrm{C}$ for 18 h. Escherichia coli (purple colonies) were counted at each dilution that was not overgrown. An appropriate dilution factor was applied to determine the number of $E$. coli per $1 \mathrm{~mL}$ of undiluted rumen fluid (cfu/mL).

From plates with at least 10 colonies, 5 putative $E$. coli colonies were picked. Isolates were then purified by repeated streaking on $E$. coli/coliform chromogenic medium. The identities of $E$. coli colonies were reconfirmed by a PCR assay specifically targeting type I fimbriae of E. coli (Table 1). Single colonies were inoculated into $15 \mathrm{~mL}$ of Luria-Bertani broth (LB; Fisher Scientific, Fairlawn, NJ) and grown for $48 \mathrm{~h}$ at $37^{\circ} \mathrm{C}$. One milliliter of fresh culture was added to $1 \mathrm{~mL}$ of $50 \%$ glycerol and stored in $-80^{\circ} \mathrm{C}$. The remainder was used for the DNA extraction.

\section{DNA Extraction}

Cells were harvested by centrifugation at $3,000 \times g$ for $15 \mathrm{~min}$. Pelleted cells were resuspended in $570 \mu \mathrm{L}$ of $0.5 \times$ Tris-EDTA buffer $(5 \mathrm{~m} M$ Tris and $0.5 \mathrm{mM}$ EDTA, pH 8.0; Fisher Scientific). Thereafter, $30 \mu \mathrm{L}$ of $10 \%$ SDS (Fisher Scientific) and $10 \mu \mathrm{L}$ of proteinase K (20 mg/mL; Fisher Scientific) were added to each tube and incubated for $1 \mathrm{~h}$ at $37^{\circ} \mathrm{C}$. Subsequently, $100 \mu \mathrm{L}$ of $5 \mathrm{M} \mathrm{NaCl}$ and $80 \mu \mathrm{L}$ of $10 \%$ cetyl trimethylammonium bromide were added to the tubes, mixed thoroughly by hand and incubated for $10 \mathrm{~min}$ at $65^{\circ} \mathrm{C}$. Then, 600 $\mu \mathrm{L}$ of phenol:chloroform:isoamylalcohol (25:24:1; Fisher Scientific) was added to the tubes, mixed and centrifuged at $10,000 \times g$ at $4^{\circ} \mathrm{C}$ for $5 \mathrm{~min}$. The supernatants were transferred to fresh tubes, mixed with $600 \mu \mathrm{L}$ of chloroform:isoamylalcohol (24:1; Fisher Scientific), and centrifuged at $10,000 \times g$ at $4^{\circ} \mathrm{C}$ for 5 min. Supernatants were transferred again to fresh microfuge tubes and mixed with equal volumes of isopropanol (Fisher Scientific) to precipitate nucleic acid. The tubes were left on ice for $15 \mathrm{~min}$ and then centrifuged at $10,000 \times$ $g$ for $10 \mathrm{~min}$. Then, pellets were washed with $500 \mu \mathrm{L}$ of $70 \%$ ethanol for 5 min and subsequently centrifuged at $10,000 \times g$ for $10 \mathrm{~min}$. The resulting nucleic acid pellets were redissolved in $100 \mu \mathrm{L}$ of $0.5 \times$ Tris-EDTA buffer $\left(\mathrm{pH}\right.$ 8.0) and stored at $-20^{\circ} \mathrm{C}$ until further analysis. The DNA concentration and purity were determined spectrophotometrically by measuring the optical density and the ratio of the absorbance at wavelength 260 and $280 \mathrm{~nm}$ (Beckman Coulter, DU/800 UV/VIS, Beckman Coulter Inc., Fullerton, CA).

\section{Rep-PCR DNA Fingerprinting}

Repetitive sequenced-based (rep)-PCR DNA fingerprinting with BOX A1R primer was used to differentiate $E$. coli isolates (Dombek et al., 2000). The method targets the interspersed, conserved, repetitive DNA 
Table 1. Primers used in this study

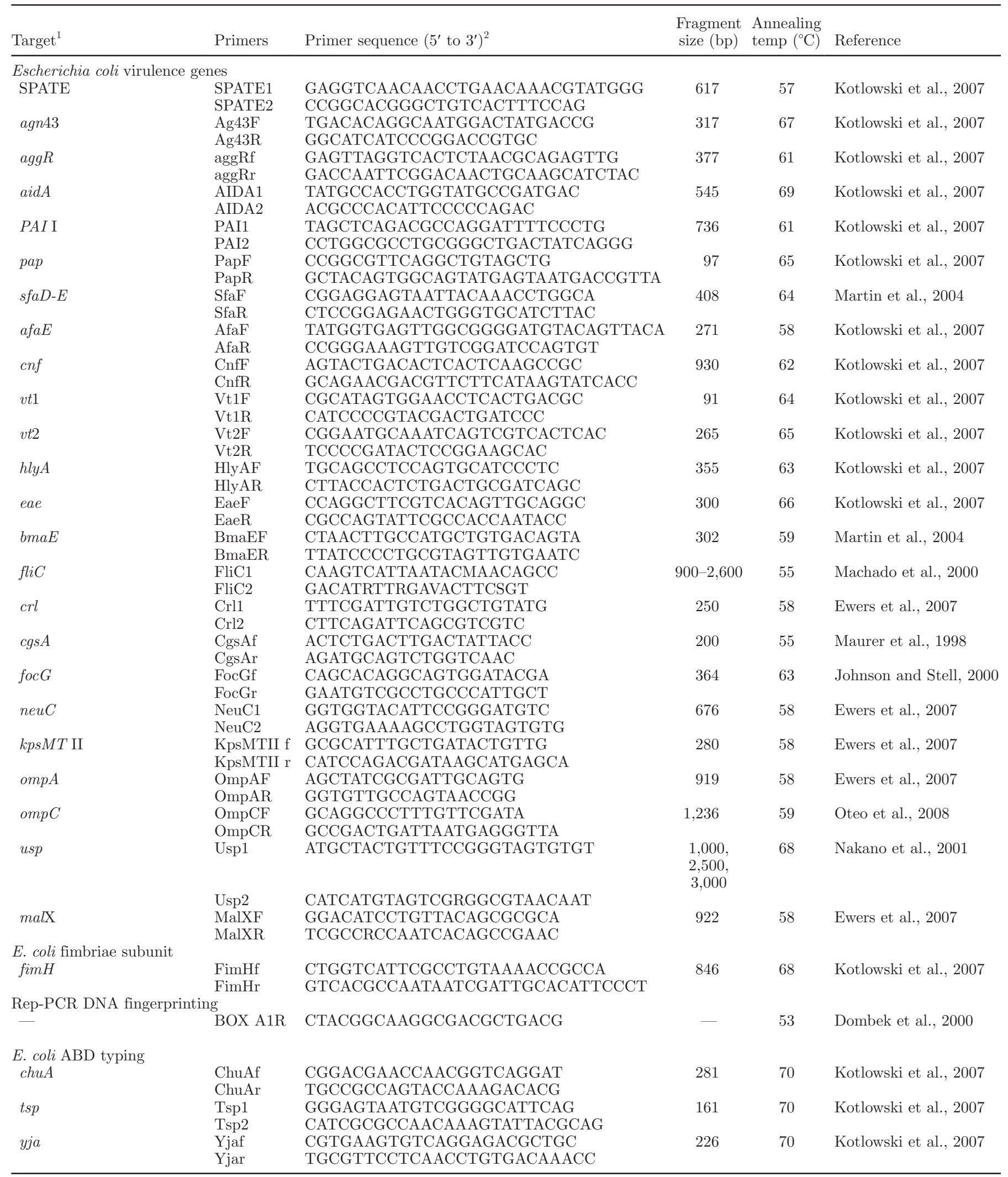


Table 1 (Continued). Primers used in this study

${ }^{1} \mathrm{SPATE}=$ genes encoding serine protease autotransporter; agn $43=$ the gene coding for antigen involved in $E$. coli autoaggregation; agg $R=$ the gene for adhesin of aggregative adherence fimbria I; aid $A=$ adhesin involved in diffuse adherence; $P A I \mathrm{I}=$ pathogenicity island I; $p a p=E$. coli Pap pili subunit and a part of pathogenicity island II; sfa = the gene coding for S-fimbriae minor subunit; afaE = gene encoding AfaE-III afimbreal adhesin involved in $E$. coli diffuse adherence; $c n f=$ cytotoxic necrotizing factors Cnf1 and Cnf2; vt 1 and vt2 = shiga toxins (verocytotoxins) 1 and $2 ; h l y A=\alpha$ hemolysin; eae = intimin; $b m a E=$ gene for M-agglutinin subunit; fliC $=$ flagellin; $c r l=$ curli regulatory gene; $c g s A$ $=$ curli structural gene which encodes curlin subunit; foc $G=\mathrm{F} 1 \mathrm{C}$ fimbriae; neuC $=\mathrm{K} 1$ capsular polysaccharide; $k p s M T I I=$ group II capsule antigens; $о m p A=$ outer membrane protein $\mathrm{A} ;$ omp $C=$ outer membrane protein $\mathrm{C}$; usp = uropathogenic-specific protein; $m a l \mathrm{X}=$ pathogenicityassociated island marker for UPEC CFT073; fim $H=$ gene encoding for adhesive subunit of $E$. coli type I fimbriae; chuA = the gene that is required for heme transport in $E$. coli $\mathrm{O} 157: \mathrm{H} 7 ; t s p=$ the gene coding for a putative DNA fragment (TSPE4.C2) in $E$. coli; yja $=$ gene coding for a protein of unknown function.

${ }^{2} \mathrm{R}=\mathrm{G}$ or $\mathrm{A} ; \mathrm{V}=\mathrm{A}$ or $\mathrm{C}$ or $\mathrm{G}$.

sequences in bacterial genome, such as REP, ERIC, or BOX elements, depending on the primer used (Mohapatra et al., 2007). Because these repetitive units are highly conserved, selective amplification of distinct genomic regions between these repetitive sequences generates unique strain-specific fingerprint patterns that can be used to differentiate E. coli.

Each $20.5-\mu \mathrm{L}$ rep-PCR reaction included $2.0 \mu \mathrm{L}$ of $10 \times$ EconoTaq buffer $(100 \mathrm{~m} M$ Tris- $\mathrm{HCl}, 500 \mathrm{~m} M \mathrm{KCl}$, $15 \mathrm{mM} \mathrm{MgCl}_{2}, 1 \%$ Triton X-100; Lucigen Corporation, Middleton, WI), $1 \mu \mathrm{L}$ of $25 \mathrm{mM} \mathrm{MgSO}_{4}$ (Fisher Scientific), $0.4 \mu \mathrm{L}$ of $10 \mathrm{~m} M$ nucleotide mix (Fisher Scientific), $0.2 \mu \mathrm{L}$ of BOX A1R primer ( $25 \mathrm{~m} M$; Table 1), 1 U EconoTaq polymerase (Lucigen Corporation), $16.2 \mu \mathrm{L}$ of $\mathrm{H}_{2} \mathrm{O}$, and $0.5 \mu \mathrm{L}$ of DNA (approximately 50 $\mathrm{ng})$. A control reaction mixture containing $0.5 \mu \mathrm{L}$ of Mili-Q water (Millipore water purification system, Millipore Corp., Billerica, MA) instead of template DNA was included in each set of PCR reactions. Amplification was performed in a Techne-Genius thermocycler with an initial denaturation step of $94^{\circ} \mathrm{C}$ for $2 \mathrm{~min}$; then 30 cycles of $94^{\circ} \mathrm{C}$ for $3 \mathrm{~s}, 92^{\circ} \mathrm{C}$ for $30 \mathrm{~s}, 53^{\circ} \mathrm{C}$ for $1 \mathrm{~min}$, and $65^{\circ} \mathrm{C}$ for $3 \mathrm{~min}$; followed by a single-step extension at $65^{\circ} \mathrm{C}$ for $8 \mathrm{~min}$ (Dombek et al., 2000). The PCR products were separated on $1.5 \%$ agarose (Promega, Madison, WI) gel and stained in a $0.5-\mu \mathrm{g} / \mathrm{mL}$ ethidium bromide solution (Fisher Scientific) for $30 \mathrm{~min}$. The gel images were captured with a FluorChem SP (Alpha Innotech Corp., San Leandro, CA). The DNA fingerprints were then analyzed for the presence or absence of 23 unique bands ranging from 420 to 3,300 bp by FluorChem SP (ver. 5.0) software, which resulted in a binary matrix that was subjected to cluster analysis. The positions of bands were normalized with external (1-kb DNA ladder) and internal standards (3 or 4 common bands between most of $E$. coli isolates) (Dombek et al., 2000).

\section{ABD Typing}

Escherichia coli isolates were assigned to 1 of the 4 groups (A, B1, B2, and D) using the methods of Clermont et al. (2000) and Kotlowski et al. (2007).
The method uses 2 genes (chuA and yjaA) and a DNA fragment (TSPE4.C2) as markers for phylogenetic grouping of isolates (Table 1). In brief, isolates belonging to $\mathrm{A}$ or $\mathrm{B} 1$ groups are negative for the chuA gene. The chuA-negative isolates are separated into TSPE4. C2 fragment-negative (A) or TSPE4.C2-positive (B1) strains. The $c h u A$-positive strains are further classified if they are $y j a A$-positive (B2), or yjaA-negative (D).

\section{Virulence Genes}

A set of 25 virulence genes (Table 1), reported in the literature to be associated with intestinal and extraintestinal virulent phylotypes of $E$. coli, including enteropathogenic E. coli, enterohemorrhagic E. coli, enterotoxigenic $E$. coli, enteroaggregative $E$. coli, enteroinvasive $E$. coli, diffusely adherent $E$. coli, avian pathogenic E. coli, and uropathogenic E. coli (UPEC), was used in this analysis. These genes encode for a range of virulence factors, including adhesins, aggregation factors, toxins, pathogenicity islands, autotransporters, and capsule synthesis.

The PCR reactions contained 50 ng of chromosomal DNA, $5 \mu \mathrm{L}$ of $10 \times$ EconoTaq buffer (Lucigen Corporation), $2 \mu \mathrm{L}$ of $\mathrm{MgCl}_{2}$ (50 $\mathrm{mM}$; Fisher Scientific), 1 $\mu \mathrm{L}$ of $10 \mathrm{~m} M$ nucleotide mix (Fisher Scientific), $1 \mu \mathrm{L}$ of each primer $(25 \mathrm{pmol}), 2$ units of EconoTaq polymerase (Lucigen Corporation), and Mili-Q water to 50 $\mu \mathrm{L}$. Thermal cycling conditions were: 1 cycle of initial denaturation $\left(95^{\circ} \mathrm{C}, 2 \mathrm{~min}\right) ; 30$ cycles of denaturation $\left(94^{\circ} \mathrm{C}, 1 \mathrm{~min}\right)$, annealing (see Table $1 ; 1 \mathrm{~min}$ ), and extension $\left(72^{\circ} \mathrm{C}, 2 \mathrm{~min}\right)$; followed by a final extension $\left(72^{\circ} \mathrm{C}, 5 \mathrm{~min}\right)$. The amplified products were subjected to electrophoresis using 1.5\% agarose (Promega) gel. Results were presented as percentage and cfu/mL of rumen fluid of $E$. coli isolates carrying virulence genes (percentage $\times$ total $\mathrm{cfu} / \mathrm{mL})$.

\section{Statistical Analysis}

The rep-PCR DNA fingerprints were clustered using the maximum composite likelihood and the unweighted pair-groups method average clustering methods 
Table 2. Escherichia coli numbers in the rumen fluid during grain pellet (GPI)- and alfalfa pellet (API)control, and GPI- and API-SARA feeding challenges

\begin{tabular}{|c|c|c|c|c|c|c|}
\hline \multirow{2}{*}{$\begin{array}{l}\text { SARA challenge/ } \\
\text { Sampling time }\end{array}$} & \multicolumn{2}{|c|}{ Number of E. coli $\left(\log _{10} \mathrm{cfu} / \mathrm{mL}\right)$ during: } & \multirow[b]{2}{*}{ SEM } & \multicolumn{3}{|c|}{ Effect, $P$-value } \\
\hline & Control diet ${ }^{1}$ & SARA diet & & Diet & Time $^{2}$ & Diet $\times$ time \\
\hline \multicolumn{7}{|l|}{ GPI } \\
\hline $0 \mathrm{~h}$ & $3.76^{\mathrm{b}}$ & $4.39^{\mathrm{ab}}$ & 0.29 & 0.69 & 0.02 & 0.01 \\
\hline $6 \mathrm{~h}$ & $5.55^{\mathrm{a}}$ & $4.74^{\mathrm{a}}$ & & & & \\
\hline \multicolumn{7}{|l|}{ API } \\
\hline $0 \mathrm{~h}$ & 1.52 & 1.45 & 0.57 & 0.51 & 0.01 & 0.55 \\
\hline $6 \mathrm{~h}$ & 2.86 & 2.35 & & & & \\
\hline
\end{tabular}

a,b Means within rows or columns with different superscripts differ $(P<0.05)$.

${ }^{1}$ Control: basal diet with a forage-to-concentrate ratio of 50:50. The forage fraction in the GPI-control consisted of $50 \%$ alfalfa silage and $50 \%$ barley silage, whereas in the API-control it consisted of chopped alfalfa hay.

${ }^{2}$ Time of rumen fluid sampling immediately before and $6 \mathrm{~h}$ after feeding. Samples were collected $4 \mathrm{~d}$ after the start of SARA induction.

(MEGA ver. 4.0; Tamura et al., 2007). The fingerprints were also subjected to discriminant functional analysis (SPSS ver. 16.0; SPSS Inc., Chicago, IL) to evaluate how accurately rep-PCR fingerprints results were able to predict the source of $E$. coli. This was achieved by calculating the percentage of isolates from a given treatment that were correctly classified to the same treatment group, termed as rate of correct classification, and calculated using discriminant functional analysis with the "leave-one-out" classification method. Chi-squared analysis based on the Mantel Haenszel method (SAS, 2004) was performed to detect significant relationships between the treatments and E. coli clusters, phylotypes, and virulence genes. Escherichia coli abundance data were analyzed using the MIXED procedure of SAS (2004). The model statement included the effects of diet (control vs. SARA) and sampling time (0 vs. 6 $\mathrm{h}$ after feeding) as fixed variables. Cow served as the random variable. Statistical differences were considered significant at $P<0.05$.

\section{RESULTS}

The abundance of $E$. coli isolated from the rumen fluid of GPI-fed cows ranged from $10^{4}$ to $10^{6} \mathrm{cfu} / \mathrm{mL}$, which was approximately 3 logs higher than in the API-fed cows (Table 2). Rumen E. coli numbers were highest at $6 \mathrm{~h}$ after feeding in both GPI- and API-fed animals; however, no differences were found in $E$. coli counts between GPI-control and GPI-SARA or APIcontrol and API-SARA (Table 2).

From the 129 isolates $(\mathrm{GPI}=80$ and $\mathrm{API}=49$; fewer colonies were obtained from the API group), 6 isolates belonging to the GPI group did not generate distinct banding patterns with rep-PCR, and were eliminated from further analysis. The DNA fingerprint patterns of the remaining 123 isolates were grouped into 6 clusters. Clustering was affected by treatment $(P=0.006$; Figure 1$)$. Approximately $74 \%$ of isolates fell into 2 major clusters (clusters 1 and 4; Figure 1). Isolates from both controls and API-SARA were closely related irrespective of the diet, so that $46 \%, 70 \%$, and $53 \%$ of isolates from GPI-control, API-control, and API-SARA, respectively, fell into cluster 4. In contrast, isolates from GPI-SARA (54\%) grouped separately in cluster 1 . The average rate of correct classification, which is defined as the percentage of isolates that can be correctly classified into their treatment group based on their fingerprint profile, was $59 \%$ of total isolates. The rate of correct classification of E. coli was $59.5 \%$ for GPI-control, $70 \%$ for API-control, $62.2 \%$ for GPISARA, and $36.8 \%$ for API-SARA (Table 3 ).

The difference in E. coli populations observed with rep-PCR was further confirmed by $\mathrm{ABD}$ typing. The ABD typing indicated a shift from an A-type E. coli population (23 control vs. 13 SARA) to a B1-type population (15 control vs. 23 SARA; $P=0.04$ ) due to GPI-SARA (Table 4). In contrast, no significant changes existed in the ABD typing groups due to APISARA. A significant relationship $(P=0.04)$ was found between $E$. coli clusters and ABD types (Figure 1). All B2-type $E$. coli were grouped in cluster 4, whereas $67 \%$ of D-type E. coli was grouped in clusters 3 and 4 . The A- and B1-type E. coli were mostly distributed in clusters 1 and 4 .

Of 25 E. coli virulence genes that we evaluated in this study (Table 1), 11 were not detected in any isolates (adhesins: afaE, agg, bmaE, ompA, sfaD-E; toxins: eae, $h l y A$, vt1, vt2; UPEC-specific protein: usp; pathogenicity island: $P A I$ ). Six virulence factors detected with low abundance in rumen E. coli (adhesins: foc $G$, pap; toxins: cnf; capsule synthesis: kpsMTII, neuC; autotransporter: SPATE). Overall, a significant difference was found between API- and GPI-fed cows in 4 virulence 
Table 3. Percentage (number) of rumen Escherichia coli from a given treatment that were correctly assigned to their group using discriminant analysis (leave-one-out classification method) of repetitive sequenced-based (rep)-PCR DNA fingerprints

\begin{tabular}{|c|c|c|c|c|c|c|}
\hline \multirow[b]{3}{*}{ Challenge } & \multirow[b]{3}{*}{ Treatment } & \multicolumn{4}{|c|}{$\%$ (no.) of E. coli isolates classified as: ${ }^{1}$} & \multirow[b]{3}{*}{ Total } \\
\hline & & \multicolumn{2}{|c|}{$\mathrm{GPI}^{2}$} & \multicolumn{2}{|c|}{$\mathrm{API}^{3}$} & \\
\hline & & Control & SARA & Control & SARA & \\
\hline \multirow[t]{2}{*}{ GPI } & Control & $59.5(22)$ & $21.6(8)$ & $16.2(6)$ & $2.7(1)$ & $100(37)$ \\
\hline & SARA & $24.3(9)$ & $62.2(23)$ & $5.4(2)$ & $8.1(3)$ & $100(37)$ \\
\hline \multirow[t]{2}{*}{ API } & Control & $6.7(2)$ & $6.7(2)$ & $70.0(21)$ & $16.7(5)$ & $100(30)$ \\
\hline & SARA & $5.3(1)$ & $26.3(5)$ & $31.6(6)$ & $36.8(7)$ & $100(19)$ \\
\hline
\end{tabular}

${ }^{1}$ Values in boldface indicate the rate of correct classification for each treatment. The average rate of correct classification was $59.3 \%$.

${ }^{2}$ Grain-pellet feeding challenge.

${ }^{3}$ Alfalfa-pellet feeding challenge.

factors. The GPI-fed animals had greater crl (adhesin; $P<0.01$ ), but fewer agn43 (adhesin with autoaggregation ability; $P<0.01$ ), maIX (pathogenicity island; $P<0.01$ ), and fliC-positive isolates (felagellin; $P=$ 0.05) compared with those of the API-fed group (Table 5). Even though the percentage of isolates carrying agn43, malX, and fliC was higher in API-fed animals, the total number of rumen $E$. coli carrying these genes was about 3 logs higher in GPI-fed cows. Similarly, for aid $A$, ompC, and $c g s A$ (all adhesins), the total rumen $E$. coli carrying them was 1,000 times higher in GPI- than API-fed animals. No significant differences existed in the prevalence of virulence genes between control and SARA periods within API or GPI (Table 5). No significant relationship was detected between E. coli clusters or ABD types and presence of virulence genes.

\section{DISCUSSION}

The majority of production diseases in dairy cows occur around the transition and early to mid-lactation periods (Mulligan and Doherty, 2008). These include

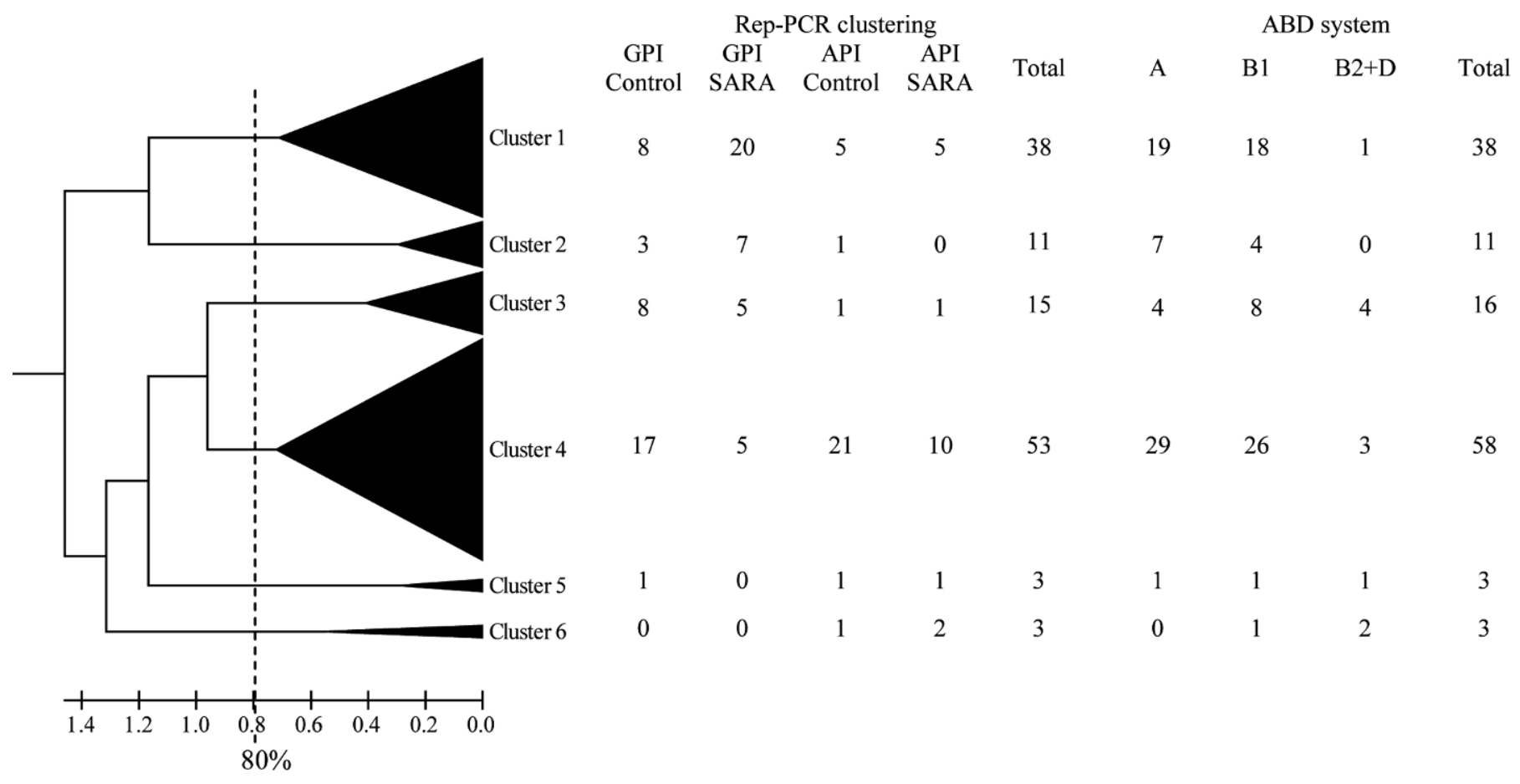

Figure 1. The relatedness of Escherichia coli strains isolated from rumen fluid of dairy cows in grain pellet (GPI)- and alfalfa pellet (API)control, and GPI- and API-SARA feeding challenges. Dendrograms were constructed from repetitive sequence-based (rep)-PCR DNA fingerprints of $E$. coli isolates using maximum composite likelihood and unweighted pair-groups method with arithmetic mean clustering methods. Values represent the number of $E$. coli isolates in each cluster/treatment group, and the distribution of A, B1, and B2+D types in each cluster. 
Table 4. Percentage (number) of rumen Escherichia coli assigned to A, B1, and B2+D groups in grain pellet (GPI)- and alfalfa pellet (API)-control, and GPI- and API-SARA feeding challenges; and statistical relationships between groups $\mathrm{A}, \mathrm{B}, \mathrm{D}$, and treatments

\begin{tabular}{|c|c|c|c|c|c|c|}
\hline \multirow[b]{3}{*}{ Item } & \multicolumn{4}{|c|}{$\%$ (no.) of $E$. coli isolates with phylotype during: } & \multicolumn{2}{|c|}{$P$-value of comparison } \\
\hline & \multicolumn{2}{|c|}{ GPI } & \multicolumn{2}{|c|}{ API } & \multirow{2}{*}{$\begin{array}{l}\text { GPI ABD } \\
\text { group }\end{array}$} & \multirow{2}{*}{$\begin{array}{l}\text { API ABD } \\
\text { group }\end{array}$} \\
\hline & Control & SARA & Control & SARA & & \\
\hline \multicolumn{7}{|l|}{ E. coli phylotype } \\
\hline A & $57.5(23)$ & $32.5(13)$ & $50.0(15)$ & $47.4(9)$ & & \\
\hline B1 & $37.5(15)$ & $57.5(23)$ & $43.3(13)$ & $36.8(7)$ & & \\
\hline $\mathrm{B} 2+\mathrm{D}$ & $5.0(2)$ & $10.0(4)$ & $6.7(2)$ & $15.8(3)$ & & \\
\hline Total & $100(40)$ & $100(40)$ & $100(30)$ & $100(19)$ & & \\
\hline \multicolumn{7}{|l|}{ ABD group } \\
\hline B1 vs. $A^{1}$ & & & & & 0.04 & 0.99 \\
\hline $\mathrm{B} 2+\mathrm{D}$ vs. $\mathrm{A}+\mathrm{B}^{2}$ & & & & & 0.61 & 0.06 \\
\hline
\end{tabular}

${ }^{1}$ Abundance of B1 vs. A in SARA compared with that in control.

${ }^{2}$ Abundance of $\mathrm{B} 2+\mathrm{D}$ vs. A+B1 in SARA compared with control.

metabolic diseases (e.g., acidosis, ketosis, and fatty liver) as well as mastitis (Mulligan and Doherty, 2008). Of these diseases, only mastitis has been associated with pathogenic microorganisms (Pyörälä, 2008), and the microbiology of acidosis has been considered only in relation to the imbalance of lactate-producing and consuming rumen bacteria (Nagaraja and Titgemeyer, 2007). Less information is available on the microbial etiology of SARA (Nagaraja and Titgemeyer, 2007; Plaizier et al., 2008). We recently published a comprehensive molecular microbial analysis of the rumen during SARA and demonstrated significant changes compared with controls (Khafipour et al., 2009c). One of the most interesting changes was related to E. coli, which we hypothesized may play a role in immune activation during SARA. The current study demonstrated that the numbers of $E$. coli in GPI- SARA were higher than API-SARA (Table 2) and that they carried virulence factors (Table 5) that could partly explain the inflammatory response associated with GPI-SARA.

Even though the numbers of $E$. coli in API-SARA cows were lower than those from GPI-SARA (Table 2 ), the concentration of free LPS in the rumen fluid was higher in API-SARA (Khafipour et al., 2009a, b). Because LPS is readily released from intact cells during their logarithmic phase of growth (Hurley, 1995),

Table 5. Distribution of virulence genes ${ }^{1}$ present in rumen Escherichia coli isolated from grain pellet (GPI)and alfalfa pellet (API)-control, and GPI- and API-SARA feeding challenges; and statistical relationships between virulence factors and challenges

\begin{tabular}{|c|c|c|c|c|c|}
\hline \multirow[b]{3}{*}{ Virulence genes } & \multicolumn{4}{|c|}{$\%$ of $E$. coli isolates (cfu/mL of rumen fluid) with virulence genes during: } & \multirow{3}{*}{$\begin{array}{l}P \text {-value of } \\
\text { API vs. GPI }{ }^{2} \\
\text { challenge }\end{array}$} \\
\hline & \multicolumn{2}{|c|}{ GPI } & \multicolumn{2}{|c|}{ API } & \\
\hline & Control & SARA & Control & SARA & \\
\hline $\operatorname{agn} 43$ & $28.9(13,059)$ & $15.0(5,509)$ & $79.4(123)$ & $78.9(63)$ & $<0.01$ \\
\hline aidA & $55.3(24,988)$ & $47.5(17,446)$ & $55.9(87)$ & $31.6(25)$ & NS \\
\hline $\operatorname{cgs} A$ & $100.0(45,186)$ & $100.0(36,728)$ & $94.1(146)$ & $100.0(79)$ & NS \\
\hline cnf & $0.0(0)$ & $0.0(0)$ & $8.8(14)$ & $0.0(0)$ & NS \\
\hline $\mathrm{crl}$ & $100.0(45,186)$ & $100.0(36,728)$ & $73.5(114)$ & $94.74(75)$ & $<0.01$ \\
\hline$f l i C$ & $71.1(32,127)$ & $70.0(25,710)$ & $94.1(146)$ & $89.5(71)$ & 0.05 \\
\hline foc $G$ & $0.0(0)$ & $0.0(0)$ & $5.9(9)$ & $0.0(0)$ & NS \\
\hline kpsMT II & $2.6(1.175)$ & $0.0(0)$ & $2.9(4)$ & $5.3(4)$ & NS \\
\hline malX & $47.4(21,418)$ & $35.0(12,855)$ & $93.9(145)$ & $52.6(42)$ & $<0.01$ \\
\hline neuC & $13.2(5,964)$ & $5.0(1,836)$ & $14.7(23)$ & $0.0(0)$ & NS \\
\hline ompC & $92.1(41,616)$ & $92.5(33,974)$ & $100.0(155)$ & $100(79)$ & NS \\
\hline рар & $2.6(1,175)$ & $0.0(0)$ & $0.0(0)$ & $0.0(0)$ & NS \\
\hline SPATE & $5.3(2,395)$ & $7.5(2,755)$ & $11.8(18)$ & $0.0(0)$ & NS \\
\hline
\end{tabular}

${ }^{1}$ Virulence genes afaE, agg, bmaE, eae, hlyA, ompA, PAII, sfaD-E, usp, vt1, and vt2 were not detected in any isolate. See Table 1 for definition of each virulence gene.

${ }^{2}$ Abundance of virulence gene in the API compared with the GPI. Statistical analyses are based on the percentage of E. coli isolates. 
this suggests that a large proportion of free rumen LPS is produced by non- $E$. coli gram-negative bacteria. However, the toxicity of LPS from other rumen gram-negative bacteria is far less than that of $E$. coli LPS (Brigham, 1994; Hurley, 1995). For example, Fibrobacter succinogenes and Bacteroides spp. in these cows were more abundant (Khafipour et al., 2009c) but it has been demonstrated that the toxicity of their LPS is low (Kaspar 1976; Nagaraja et al., 1979a, b). The limulus amebocyte lysate test that we used measures total LPS but does not assess differences in the toxicity of LPS molecules (Hurley, 1995). Thus, even if E. coli numbers are relatively low compared with those of other gram-negative bacteria, their contribution to the pathophysiology of SARA is likely to be greater because they have greater virulence potential than Bacteroides spp. and F. succinogenes (Kaspar 1976; Nagaraja et al., 1979a, b).

Feeding alfalfa pellets or grain caused significant reductions in rumen $\mathrm{pH}$ and increased osmolarity (Khafipour et al., 2009a, b). With both diets, parakeratosis of the rumen epithelium may result (Hinders and Owen, 1965; Tamate et al., 1978; Steele et al., 2009). Hinders and Owen (1965) fed alfalfa pellets or long hay, and observed that animals on the pelleted alfalfa diet had reddening and slight hypertrophy of the rumen papillae within 2 wk, which became rough with multiple localized adhesions after wk 3 . In a case report, Steele et al. (2009) transitioned a dairy cow from a high-forage diet to a high-concentrate diet (79\%) for 1 wk and observed extensive sloughing of the stratum corneum of rumen papillae and abnormally high numbers of nondifferentiated keratinocytes, which is a hallmark of parakeratosis.

In a healthy rumen, keratinized cells cover the epithelium, but during parakeratosis the rate of cellular differentiation and the movement of cells toward the surface are increased so that the time necessary for complete keratinization is reduced to below a minimum, and thus, an abnormally high proportion of immature nonkeratinized cells reach the surface of the epithelium (Dirksen et al., 1984). Gálfi et al. (1998) cultured E. coli in the presence of keratinized and nonkeratinized cells and demonstrated that nonkeratinized cells bound more E. coli than did keratinized cells. Semjén and Galfi (1990) demonstrated that E. coli preferentially adhered to cultured nonkeratinized rumen epithelial cells with type I fimbriae and caused mannose sensitive hemagglutination. There appears to be a general reduction of attachment sites for E. coli when epithelia are keratinized (Semjén et al., 1982). On the other hand, lower microbial diversity on parakeratotic epithelia (Steele et al., 2009) potentially increases the opportunity for E. coli attachment. The change in microbial popula- tion competition at the epithelia likely also changes the composition of $E$. coli to a population that is able to take advantage of a SARA environment (Table 4, Figure 1).

In our experiments, E. coli were isolated from the rumen of animals on either API or GPI diets with low $\mathrm{pH}(250-550$ min below $\mathrm{pH} 5.6)$ and high osmolarity (330 mOsm $/ \mathrm{kg}$ ) (Khafipour et al., 2009a, b). Although the rumen epithelia in these animals were not examined, we can assume, based on the literature (Hinders and Owen, 1965; Tamate et al., 1978; Steele et al., 2009), that parakeratosis was present. Thus, in both diets, nonkeratinized rumen epithelia would have been available for binding to $E$. coli, but the number of rumen $E$. coli in the GPI-SARA was approximately 1,000 times higher than in the API-SARA (Table 2), which would have increased the opportunity of the bacterium to take advantage of binding sites. The availability of readily fermentable carbohydrate results in an increase in the abundance of $E$. coli in the rumen (Russell et al., 2000; Krause et al., 2003), and the inclusion of forage reduces $E$. coli abundance (Callaway et al., 2009). We concluded that low rumen $\mathrm{pH}$ and high osmolarity alone, although damaging to the rumen epithelium, are not enough to cause immune activation during SARA. An energy source, such as nonstructural carbohydrate that can be used by pathogenic bacteria like E. coli is also required.

For E. coli to exert a pathogenic effect, it would likely have to possess a combination of virulence factors that help the bacterium attach to nonkeratinized epithelial cells, invade the host, avoid or disrupt host defense mechanisms, injure the host tissue, and stimulate an inflammatory response (Johnson and Stell, 2000). Our results showed that E. coli from either GPI- or APISARA were less likely to possess genes encoding for enterotoxins ( $c n f$, eae, hlyA, vt1, vt2; Table 5). In contrast, genes encoding for adhesins were more abundant but were not found exclusively in the isolates from GPI and were also present in API isolates, indicating that these potential pathogens are always present but it is the availability of readily fermentable carbohydrate from grain that results in an increase in abundance of the bacterium and, consequently, its association with disease.

A significant $(P<0.01)$ association existed between E. coli possessing curli fibers $(\mathrm{crl})$ and GPI group (Table 5). Curli fibers are protein components of a complex extracellular matrix produced by E. coli and were first discovered in E. coli strains that caused bovine mastitis (Olsén et al., 1989). Curli fibers enable adhesion to surfaces, cell aggregation, and biofilm formation. They may also induce host cell adhesion and invasion, and upregulate the host inflammatory response. It is, thus, 
plausible that curli fiber-associated $E$. coli reside in the rumen and under appropriate physiological conditions (e.g., parakeratosis of rumen wall) cause inflammation of the rumen epithelium. This hypothesis supports our previous observation that mediators of inflammatory response were increased only due to GPI-SARA (Khafipour et al., 2009a, b).

The higher numbers of E. coli associated with GPISARA also had higher pathogenic potential because a larger population of the bacterium possessed virulence factors agn 43 , aidA, cgsA, fliC, ompC, and malX (Table 5). A large population of $E$. coli is essential for the expression of its virulence genes because the gene expression is regulated in response to cell density by quorum sensing (Ng and Bassler, 2009). Quorum sensing, or cell-to-cell communication, is a method by which $E$. coli coordinates its population behavior in response to its own population density or that of other members of the microbiome, as well as the activity of the host (Anand and Griffiths, 2003). This allows E. coli to act in unison, and to appropriately time the expression of virulence factors when the bacteria are in sufficient numbers to overwhelm the host defense (Anand and Griffiths, 2003).

Among the above-mentioned virulence genes, agn 43 and aidA encode antigen 43 and AIDA-I proteins, respectively. Like curli fibers, these proteins facilitate $E$. coli adhesion to the epithelial surface (Le Bouguenec, 2005). Antigen 43 and AIDA-I also have a major role in aggregation and biofilm formation of the E. coli (Henderson et al., 2004; Hatt and Rather, 2008), an ability that increases bacterial resistance to host defense mechanisms. In addition, cgs $A$ is a key virulence gene that encodes the curlin subunit of the curli fibers and its expression is regulated by $\mathrm{crl}$ (Maurer et al., 1998). These results suggest that rumen E. coli has evolved to produce several adhesins that are essential for the bacterium pathogenesis.

In conclusion, we have identified genes in rumen $E$. coli for curli fiber synthesis that are potent virulence factors. Furthermore, we have demonstrated that under low rumen $\mathrm{pH}$ conditions induced by a high-grain diet, there is a burst in the number of $E$. coli with virulence genes that can take advantage of these rumen conditions to trigger an inflammatory response.

\section{ACKNOWLEDGMENTS}

This study was supported by grants from Dairy Farmers of Canada (DFC), the Agri-Food Research Development Initiative (ARDI), and the Natural Sciences and Engineering Research Council of Canada (NSERC). The authors thank Shadi Sepehri from Department of Medical Microbiology and Infectious Diseases and
Angela Kroeker from Department of Animal Science at University of Manitoba for their assistance in selection of virulence genes and laboratory analysis. P. C. Aikman is grateful to the British Grassland Society for supporting her visit to the University of Manitoba with a Stapledon Memorial Trust Travelling Fellowship.

\section{REFERENCES}

Anand, S. K., and M. W. Griffiths. 2003. Quorum sensing and expression of virulence in Escherichia coli O157:H7. Int. J. Food Microbiol. 85:1-9.

Brigham, K. L. 1994. Endotoxin and the Lungs. Marcel Dekker Inc., New York, NY.

Callaway, T. R., M. A. Carr, T. S. Edrington, R. C. Anderson, and D. J. Nisbet. 2009. Diet, Escherichia coli O157:H7, and cattle: A review after 10 years. Curr. Issues Mol. Biol. 11:67-79.

Canadian Council on Animal Care. 1993. Guide to the care and use of experimental animals. 2nd ed., vol. 1. Ottawa, ON, Canada.

Clermont, O., S. Bonacorsi, and E. Bingen. 2000. Rapid and simple determination of the Escherichia coli phylogenetic group. Appl. Environ. Microbiol. 66:4555-4558.

Dirksen, G., H. G. Liebich, G. Brosi, H. Hagemeister, and E. Mayer. 1984. Morphology of the rumen mucosa and fatty acid absorption in cattle-Important factors for health and production. Zentralbl. Veterinarmed. A. 31:414-430.

Dombek, P. E., L. K. Johnson, S. T. Zimmerley, and M. J. Sadowsky. 2000. Use of repetitive DNA sequences and the PCR to differentiate Escherichia coli isolates from human and animal sources. Appl. Environ. Microbiol. 66:2572-2577.

Ewers, C., G. W. Li, H. Wilking, S. Kiessling, K. Alt, E. M. Antao, C. Laturnus, I. Diehl, S. Glodde, T. Homeier, U. Bohnke, H. Steinruck, H. C. Philipp, and L. H. Wieler. 2007. Avian pathogenic, uropathogenic, and newborn meningitis-causing Escherichia coli: How closely related are they? Int. J. Med. Microbiol. 297:163-176.

Gálfi, P., S. Neogrády, G. Semjén, S. Bardocz, and A. Pusztai. 1998. Attachment of different Escherichia coli strains to cultured rumen epithelial cells. Vet. Microbiol. 61:191-197.

Hatt, J. K., and P. N. Rather. 2008. Role of bacterial biofilms in urinary tract infections. Curr. Top. Microbiol. Immunol. 322:163192.

Henderson, I. R., F. Navarro-Garcia, M. Desvaux, R. C. Fernandez, and D. Ala'Aldeen. 2004. Type V protein secretion pathway: The autotransporter story. Microbiol. Mol. Biol. Rev. 68:692-744.

Herigstad, B., M. Hamilton, and J. Heersink. 2001. How to optimize the drop plate method for enumerating bacteria. J. Microbiol. Methods 44:121-129.

Hinders, R. G., and F. G. Owen. 1965. Relation of ruminal parakeratosis development to volatile fatty acid absorption. J. Dairy Sci. 48:1069-1073.

Hurley, J. C. 1995. Endotoxemia: Methods of detection and clinical correlates. Clin. Microbiol. Rev. 8:268-292.

Johnson, J. R., and A. L. Stell. 2000. Extended virulence genotypes of Escherichia coli strains from patients with urosepsis in relation to phylogeny and host compromise. J. Infect. Dis. 181:261-272.

Kasper, D. L. 1976. Chemical and biological characterization of the lipopolysaccharide of Bacteroides fragilis subspecies fragilis. J. Infect. Dis. 134:59-66.

Khafipour, E., D. O. Krause, and J. C. Plaizier. 2009a. A grainbased subacute ruminal acidosis challenge causes translocation of lipopolysaccharide and triggers inflammation. J. Dairy Sci. 92:1060-1070.

Khafipour, E., D. O. Krause, and J. C. Plaizier. 2009b. Alfalfa pelletinduced subacute ruminal acidosis in dairy cows increases bacterial endotoxin in the rumen without causing inflammation. J. Dairy Sci. 92:1712-1724.

Khafipour, E., S. Li, J. C. Plaizier, and D. O. Krause. 2009c. Rumen microbiome composition using two nutritional models of subacute ruminal acidosis (SARA). Appl. Environ. Microbiol. 75:71157124 . 
Kleen, J. L., G. A. Hooijer, J. Rehage, and J. P. Noordhuizen. 2003. Subacute ruminal acidosis (SARA): A review. J. Vet. Med. A Physiol. Pathol. Clin. Med. 50:406-414.

Kotlowski, R., C. N. Bernstein, S. Sepehri, and D. O. Krause. 2007. High prevalence of Escherichia coli belonging to the B2+D phylogenetic group in inflammatory bowel disease. Gut 56:669-675.

Krause, D. O., W. J. Smith, L. L. Conlan, J. M. Gough, M. A. Williamson, and C. S. McSweeney. 2003. Diet influences the ecology of lactic acid bacteria and Escherichia coli along the digestive tract of cattle: Neural networks and $16 \mathrm{~S}$ rDNA. Microbiololgy 149:57-65.

Le Bouguénec, C. 2005. Adhesins and invasins of pathogenic Escherichia coli. Int. J. Med. Microbiol. 295:471-478.

Machado, J., F. Grimont, and P. A. Grimont. 2000. Identification of Escherichia coli flagellar types by restriction of the amplified fliC gene. Res. Microbiol. 151:535-546.

Martin, H. M., B. J. Campbell, C. A. Hart, C. Mpofu, M. Nayar, R. Singh, H. Englyst, H. F. Williams, and J. M. Rhodes. 2004. Enhanced Escherichia coli adherence and invasion in Crohn's disease and colon cancer. Gastroenterology 127:80-93.

Maurer, J. J., T. P. Brown, W. L. Steffens, and S. G. Thayer. 1998 The occurrence of ambient temperature-regulated adhesins, curli, and the temperature-sensitive hemagglutinin tsh among avian Escherichia coli. Avian Dis. 42:106-118.

Mohapatra, B. R., K. Broersma, R. Nordin, and A. Mazumder. 2007. Evaluation of repetitive extragenic palindromic-PCR for discrimination of fecal Escherichia coli from humans, and different domestic- and wild-animals. Microbiol. Immunol. 51:733-740.

Mulligan, F. J., and M. L. Doherty. 2008. Production diseases of the transition cow. Vet. J. 176:3-9.

Nagaraja, T. G., E. E. Bartley, L. R. Fina, H. D. Anthony, B. E Brent, and D. A. Sapienza. 1979a. Chemical characteristics of rumen bacterial endotoxin. J. Anim. Sci. 48:1250-1256.

Nagaraja, T. G., L. R. Fina, B. A. Lassman, E. E. Bartley, H. D. Anthony, D. A. Sapienza, and B. E. Brent. 1979b. Characterization of endotoxin from the rumen bacterium Megasphaera elsdenii. Am. J. Vet. Res. 40:35-39.

Nagaraja, T. G., and E. C. Titgemeyer. 2007. Ruminal acidosis in beef cattle: The current microbiological and nutritional outlook. J. Dairy Sci. 90(E. Suppl.): E17-E38.

Nakano, M., S. Yamamoto, A. Terai, O. Ogawa, S. Makino, H. Hayashi, G. B. Nair, and H. Kurazono. 2001. Structural and se- quence diversity of the pathogenicity island of uropathogenic Escherichia coli which encodes the USP protein. FEMS Microbiol. Lett. 205:71-76.

Ng, W. L., and B. L. Bassler. 2009. Bacterial quorum-sensing network architectures. Annu. Rev. Genet. 43:197-222.

Olsén, A., A. Jonsson, and S. Normark. 1989. Fibronectin binding mediated by a novel class of surface organelles on Escherichia coli. Nature 338:652-655.

Oteo, J., A. Delgado-Iribarren, D. Vega, V. Bautista, M. C. Rodriguez, M. Velasco, J. M. Saavedra, M. Perez-Vazquez, S. Garcia-Cobos, L. Martinez-Martinez, and J. Campos. 2008. Emergence of imipenem resistance in clinical Escherichia coli during therapy. Int. J. Antimicrob. Agents 32:534-537.

Plaizier, J. C., D. O. Krause, G. N. Gozho, and B. W. McBride. 2008. Subacute ruminal acidosis in dairy cows: The physiological causes, incidence and consequences. Vet. J. 176:21-31.

Pyörälä, S. 2008. Mastitis in post-partum dairy cows. Reprod. Domest. Anim. 43:252-259.

Russell, J. B., F. Diez-Gonzalez, and G. N. Jarvis. 2000. Invited review: Effects of diet shifts on Escherichia coli in cattle. J. Dairy Sci. 83:863-873.

SAS. 2004. SAS/stat Users Guide, release 9.1.2. SAS Inst., Inc., Cary, NC.

Semjén, G., and P. Galfi. 1990. Factors influencing the adherence of strains of Streptococcus bovis and Escherichia coli isolated from ruminal epithelium. Vet. Res. Commun. 14:181-191.

Semjén, G.. P. Galfi, and F. Kutas. 1982. Effect of parakeratosis on bacterial adherence to ruminal epithelium. Zentralb. Vet. Med. B 29:317-319.

Steele, M. A., O. AlZahal, S. E. Hook, J. Croom, and B. W. McBride. 2009. Ruminal acidosis and the rapid onset of ruminal parakeratosis in a mature dairy cow: A case report. Acta Vet. Scand. $51: 39$.

Tamate, H., S. Yoneya, T. Sakata, S. Omori, and M. Kato. 1978. Rumen parakeratosis and acute rumenitis in the calves fed on highconcentrate rations: An experimental survey. Tohoku J. Agric. Res. 29:29-37.

Tamura, K., J. Dudley, M. Nei, and S. Kumar. 2007. MEGA4: Molecular evolutionary genetics analysis (MEGA) software version 4.0 Mol. Biol. Evol. 24:1596-1599. 